\title{
Laparoscopic correction of the uterine muscle loss in the scar after a Caesarean section delivery
}

\author{
Michał Ciebiera, Grzegorz Jakiel, Aneta Słabuszewska-Jóźwiak \\ $1^{\text {st }}$ Department of Obstetrics and Gynaecology, Medical Centre of Postgraduate Education, Warsaw, Poland
}

Videosurgery Miniinv 2013; 8 (4): 342-345

DOI: 10.5114/wiitm.2013.39514

\begin{abstract}
Caesarean section is the most frequently conducted surgery in modern obstetrics. It involves a significant risk of complications; also disorders in the area of the scar after hysterotomy may lead to menstrual disorders, pain and secondary infertility. In light of the presented facts the significance of a good uterus muscle correction method is high. We present a case of a 28-year-old patient after Caesarean section with further reproductive plans. In the ultrasonographic examination the residual thickness of the uterine wall was approx. 2.5-3 $\mathrm{mm}$. The patient was operated on using laparoscopy and the fibrotic scar tissue was removed. During the follow-up examination in transvaginal ultrasonography the uterine muscularis was continuous on the whole surface. Laparoscopic treatment ensures the appropriate visibility which makes the risk of damage to the adjacent organs lower, and the time of convalescence is short. It provides repetitive good results from the anatomical and functional points of view.
\end{abstract}

Key words: Caesarean section, laparoscopy, uterine scar, minimally invasive surgery.

\section{Introduction}

A Caesarean section is the most frequently conducted surgery in modern obstetrics and it consists in a surgical incision of skin integuments, as well as an incision of the anterior wall of the uterus, after which a child is delivered. For a few decades a big increase has been observed in the number of pregnancies finished with the use of this method $[1,2]$. A Caesarean section involves a significant risk of complications. Research has shown that the first Caesarean section increases the risk of a Caesarean section during the following pregnancy [3]. There is also scientific evidence which proves other unfavourable consequences connected with a Caesarean section, such as an increased risk of a uterine rupture at natural birth, an incorrect location of a placenta during the following pregnancies, a pregnancy in the scar, and the dehiscence of the scar after a Caesarean section [4-9]. Disorders within the area of a scar after a Caesarean section delivery may constitute aetiological factors for menstrual disorders, painful menstruations, intermenstrual bleeding, and also the cause of secondary infertility [10-17]. In case of incorrect healing the risk of loss within the muscularis increases, which is, in the professional literature, referred to as the "isthmocele" or "niche" [16, 17].

In light of the presented facts the significance of the correction method of undesirable consequences of the surgery is high and continues to rise. This procedure aims to restore the continuity of the uterine muscle, which consequently leads to a reduction of ailments related to incorrect healing of the myometrium. In this article we present the application of a laparoscopic technique for the correction of the 
uterine muscle loss after a Caesarean section, which restores the correct build of the female genital tract.

\section{Case report}

In 2013 a 28-year-old female patient was admitted to the clinic, in whom during the transvaginal ultrasonographic examination a loss of uterine muscle after a Caesarean section conducted in 2010 was found. The Caesarean section was carried out in the lower part of the body of the uterus cross-wise and suprapubically because of intrauterine asphyxia of the fetus in the first period of the labour. After the surgery and in the early period of puerperium no complications were observed. Currently the patient was admitted to the hospital for diagnosis and treatment of that lesion (the patient had further reproductive plans). During the hospitalisation in the clinic the transvaginal ultrasonographic examination revealed anteflexed body of the uterus with homogeneous echogenicity divided within the anterior wall of the uterus, in the area of the uterine isthmus, with a triangular area with visible loss of endometrium; the lesion was located in the scar after the Caesarean section (Photo 1).

The residual thickness of the wall was approx. 2.5-3 mm. Left uterine appendages with vesicles up to $12 \mathrm{~mm}$, right uterine appendages without visible pathological lesions. In laboratory tests (morphology, coagulation parameters, kidney function parameters, glycaemia) no deviations from the norm were found. (red blood cells $-5.05 \mathrm{M} / \mu \mathrm{l}$, hemoglobin $-13.18 \mathrm{~g} / \mathrm{dl}$, hematocrit $-43.3 \%)$. No contraindications having been found, the patient was qualified for laparoscopy with correction of the scar after a Caesarean section.

Under general anaesthesia, in the Trendelenburg position, after disinfection of the surgical opening, through the navel a $10 \mathrm{~mm}$ trocar (Karl Storz HD optics) was inserted into the peritoneal cavity. Next, under visual control two $5 \mathrm{~mm}$ trocars were inserted through the skin from the left and right side of the abdomen. The body of the uterus was of the correct size and mobility, left and right appendages were without visible pathological lesions and the parietal peritoneum was smooth; on the body of the uterus a scar after the Caesarean section was revealed. After dissection of the bladder, the fibrotic scar tissue from the uterine muscle was removed at the length of $2 \mathrm{~cm}$. The uterine muscle was sewn again using 4 single sutures (Vicryl VCP 9213H); the peritoneum was not sewn. No signs of active bleeding were found. In the peritoneal cavity $300 \mathrm{ml}$ of colloidal solution hydroxyethyl starch solution (HES) was left. After desufflation single nonabsorbable sutures were applied. Changes in urine were not visible. The loss of blood was minimal. The whole surgical procedure lasted approx. $45 \mathrm{~min}$. The early stay of the patient at the ward after the procedure was without complications. During laboratory tests no deviations from the norm were found (red blood cells $4.67 \mathrm{M} / \mu \mathrm{l}$, hemoglobin $13.2 \mathrm{~g} / \mathrm{dl}$, hematocrit $40.8 \%$ ). The patient was discharged within the next $24 \mathrm{~h}$ after the procedure in a generally good condition with recommendations to control and remove sutures from the skin during the $8^{\text {th }}$ day after the procedure.

After 4 weeks during the follow-up visit in a bimanual examination of the genital tract no deviations from the correct state were found. In transvaginal ultrasonography the muscularis of the body of the uterus was continuous on the whole surface (Photo 2).

\section{Discussion}

The percentage of women in whom a Caesarean section is conducted is increasing; consequently, the risk of abnormalities within the area of the delivery scar in the uterine muscle is also increasing. Severe complications, such as fracture of the uterine muscle and subsequent haemorrhage, regardless of the achievements of medicine, can still constitute a threat to health and life of a mother and fetus [4-9]. An important aspect is the influence of the lesion on the problems connected with getting pregnant. The "isthmocele" may

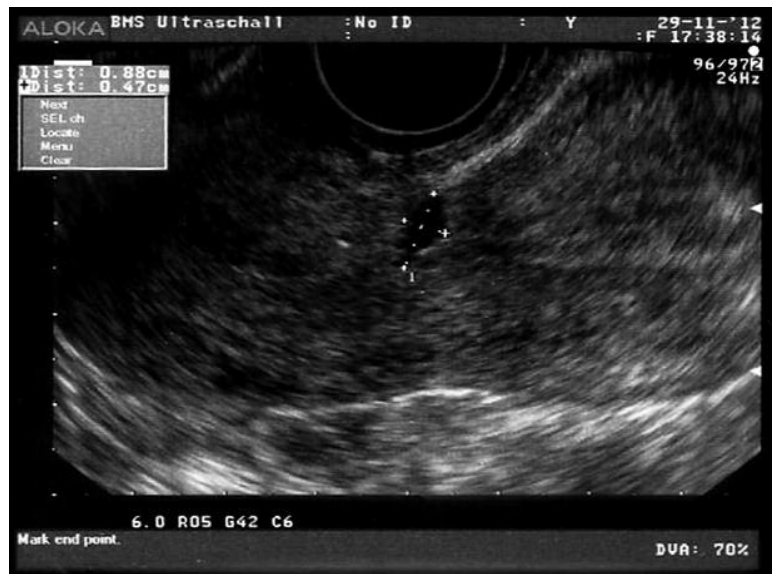

Photo 1. Uterus with visible loss of the anterior wall (transvaginal ultrasonography) 


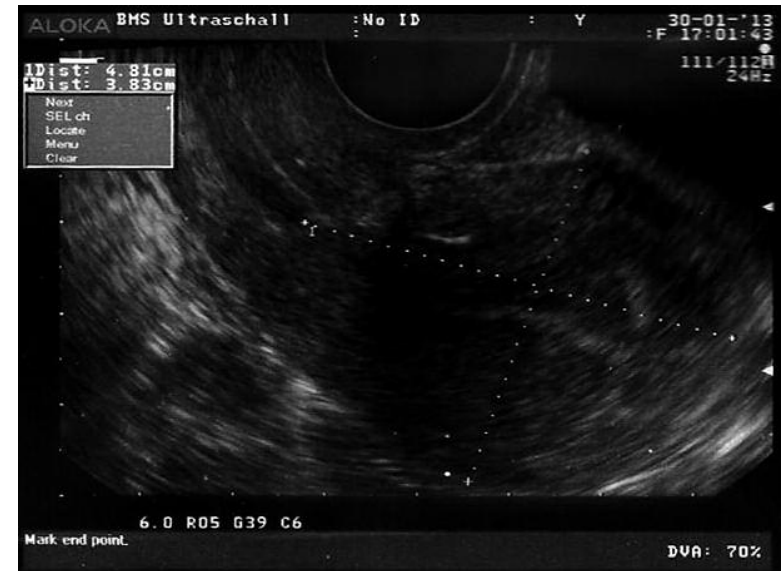

Photo 2. Uterus after laparoscopic correction, follow-up examination (transvaginal ultrasonography)

lead to changes in the cervical mucus, and gathering of menstrual blood in the niche of the muscularis, which may result in difficulties for a spermatozoid and the creation of a toxic environment for the implanting fetus $[8,13,18,19]$. Vikhareva Osser et al. presented risk factors for incomplete healing of uterine incision after a Caesarean section as follows: prolonged birth (especially over $10 \mathrm{~h}$ ), high degree of delivery advancement (high dilation of the cervix, the use of oxytocin during labour, intra-operative complications, retroverted uterus; the way a Caesarean section is conducted is also highly influential [20-22]). The subsequent symptoms and ailments within the abdomen, incorrect uterine bleeding or breakthrough bleeding, problems with urinating, recurring urinary tract infections, or secondary infertility can be the result of a loss of uterine muscle $[11,13-17,23]$. The presence of these ailments should not be ignored; in each case detailed imaging diagnostics should be applied and in case of further maternity plans and coexistence of an incision scar longer than $3 \mathrm{~mm}$ an ultrasonographic examination of the lower part of the uterus should be proposed, and in case of an incision scar shorter than $3 \mathrm{~mm}$ before pregnancy optimal operative treatment should be implemented. If a patient does not have further procreation plans and does not report ailments, an annual ultrasonographic examination is applied. However, if the loss of uterine muscle is accompanied by symptoms (abdominal pain, breakthrough bleeding, etc.), depending on the thickness of the muscularis which is left, appropriate operative treatment is applied [24].
Diagnostics of "isthmocele" includes, apart from interview and physical examination, methods of imaging diagnostics such as transvaginal ultrasonography (playing the most important role) [11, 12, 23, 25-29], and magnetic resonance imaging [30]. A USG examination should be conducted after the occurrence of vaginal bleeding, because it improves the visibility of the lesion [27]. Filling the uterine cavity with a contrast fluid (sonohysterography) also facilitates the diagnosis $[10,14,16,31]$. The niche is visible during the examination as a triangular hypoechogenic area, with its apex directed towards the anterior wall of the uterine isthmus, whereas the base is directed towards its posterior wall. Other methods used in "isthmocele" diagnostics are endoscopic techniques (mainly hysteroscopy) [10, 13, 18, 23, 27, $28,32,33]$.

Nowadays a popular technique for the correction of muscle loss in the incision scar after a Caesarean section is operative hysteroscopy $[13,18,23,28,32$, 33]. Nevertheless, only the use of laparoscopy ensures appropriate visibility of the surgical opening (the possibility to dissect the bladder), lower risk of damage to adjacent organs, and also very short time of convalescence after the procedure $[12,24,34,35]$. Due to the enumerated advantages laparoscopy has chances to become a leading technique in the coming years.

\section{Conclusions}

The loss of uterine muscle in the incision scar after a Caesarean section conditions many ailments in women who undergo this procedure. Appropriate imaging diagnostics should be implemented which will allow verification of a group of female patients who should be treated surgically. The presented laparoscopic technique allowed complete correction of the incorrect lesion within the area of the scar. Laparoscopic removal of the niche is a technique which provides repetitive good results for the genital tract both from the anatomical and functional points of view.

\section{References}

1. Althabe F, Sosa C, Belizan JM, et al. Cesarean section rates and maternal and neonatal mortality in low-, medium-, and highincome countries: an ecological study. Birth 2006; 33: 270-7.

2. Betran AP, Merialdi M, Lauer JA, et al. Rates of caesarean section: analysis of global, regional and national estimates. Paediatr Perinat Epidemiol 2007; 21: 98-113. 
3. MacDorman MF, Menacker F, Declercq E. Cesarean birth in the United States: epidemiology, trends, and outcomes. Clin Perinatol 2008; 35: 293-307.

4. Kennare R, Tucker G, Heard A, et al. Risks of adverse outcomes in the next birth after a first cesarean delivery. Obstet Gynecol 2007; 109: 270-6.

5. Ash A, Smith A, Maxwell D. Caesarean scar pregnancy. BJOG 2007; 114: 253-63.

6. Kayani SI, Alfirevic Z. Uterine rupture after induction of labour in women with previous cesarean section. Br J Obstet Gynaecol 2005; 112: 451-5.

7. Harper LM, Macones GA. Predicting success and reducing the risks when attempting vaginal birth after cesarean. Obstet Gynecol Surv 2008; 63: 538-45.

8. Diaz SD, Jones JE, Seryakov M, et al. Uterine rupture and dehiscence: ten-year review and case-control study. South Med I 2002; 95: 431-5.

9. Guise JM, McDonagh MS, Osterweil P, et al. Systematic review of the incidence and consequences of uterine rupture in women with previous caesarean section. BMJ 2004; 329: 19-25.

10. Chang Y, Tsai EM, Long CY, et al. Resectoscopic treatment combined with sonohysterographic evaluation of women with postmenstrual bleeding as a result of previous cesarean delivery scar defects. Am J Obstet Gynecol 2009; 200: 370.e1-4.

11. Uppal T, Lanzarone V, Mongelli M. Sonographically detected caesarean section scar defects and menstrual irregularity. J Obstet Gynaecol 2011; 31: 413-6.

12. Klemm P, Koehler C, Mangler M, et al. Laparoscopic and vaginal repair of uterine scar dehiscence following caesarean section as detected by ultrasound. J Perinat Med 2005; 33: 324-31,

13. Fabres C, Arriagada P, Fernandez C, et al. Surgical treatment and follow-up of women with intermenstrual bleeding due to cesarean section scar defect. J Minim Invasive Gynecol 2005; 12: 25-8.

14. Thurmond AS, Harvey WJ, Smith SA. Cesarean section scar as a cause of abnormal vaginal bleeding: diagnosis by sonohysterography. J Ultrasound Med 1999; 18: 13-6.

15. Van Horenbeeck A, Temmerman M, Dhont M. Cesarean scar dehiscence and irregular uterine bleeding. Obstet Gynecol 2003; 102: 1137-9.

16. Monteagudo A, Carreno C, Timor-Tritsch IE. Saline infusion sonohysterography in nonpregnant women with previous cesarean delivery: the 'niche' in the scar. J Ultrasound Med 2001; 20: 1105-15.

17. Gubbini G, Casadio P, Marra E. Resectoscopic correction of the isthmocele in women with postmenstrual abnormal uterine bleeding and secondary infertility. J Minim Invasive Gynecol 2008; 15: 172-5.

18. Florio P, Filippeschi M, Moncini I, et al. Hysteroscopic treatment of the cesarean-induced isthmocele in restoring infertility. Curr Opin Obstet Gynecol 2012; 24: 180-6.

19. Guzeloglu-Kayisli O, Kayisli UA, Taylor HS. The role of growth factors and cytokines during implantation: endocrine and paracrine interactions. Semin Reprod Med 2009; 27: 62-79.

20. Vikhareva Osser O, Valentin L. Risk factors for incomplete healing of the uterine incision after caesarean section. BJOG 2010; 117: $1119-26$
21. Bujold E, Goyet M, Marcoux S, et al. The role of uterine closure in the risk of uterine rupture. Obstet Gynecol 2010; 116: 43-50.

22. Roberge S, Chaillet N, Boutin A, et al. Single-versus doublelayer closure of the hysterotomy incision during caesarean delivery and risk of uterine rupture. Int J Gynaecol Obstet 2011; 115: 5-10.

23. Fabres C, Alam V, Balmaceda J, et al. Comparison of ultrasonography and hysteroscopy in the diagnosis of intrauterine lesions in infertile women. J Am Assoc Gynecol Laparosc 1998; 5: 375-8.

24. Marotta ML, Donnez J. Laparoscopic repair of post-Cesarean section uterine scar defects diagnosed in nonpregnant women. J Minim Invasive Gynecol 2013; 20: 386-91.

25. Sen S, Malik S, Salhan S. Ultrasonographic evaluation of lower uterine segment thickness in patients of previous caesarean section. Int J Gynecol Obstet 2004; 87: 215-9.

26. Osser OV, Jokubkiene L, Valentin L. High prevalence of defects in Cesarean section scars at transvaginal ultrasound examination. Ultrasound Obstet Gynecol 2009; 34: 90-7.

27. Fabres C, Aviles G, De La Jara C, et al. The cesarean delivery scar pouch: clinical implications and diagnostic correlation between transvaginal sonography and hysteroscopy. I Ultrasound Med 2003; 22: 695-700.

28. Ceci O, Cantatore C, Scioscia M, et al. Ultrasonographic and hysteroscopic outcomes of uterine scar healing after cesarean section: comparison of two types of single-layer suture. J Obstet Gynaecol Res 2012; 38: 1302-7.

29. Vikhareva Osser O, Valentin L. Clinical importance of appearance of Cesarean hysterotomy scar at transvaginal ultrasonography in nonpregnant women. Obstet Gynecol 2011; 117: 525-32.

30. Dicle O, Kucukler C, Pirnar T, et al. Magnetic resonance imaging evaluation of incision healing after caesarean sections. Eur Radiol 1997; 7: 31-4.

31. Osser OV, Jokubkiene L, Valentin L. Cesarean section scar defects: agreement between transvaginal sonographic findings with and without saline contrast enhancement. Ultrasound Obstet Gynecol 2010; 35: 75-83.

32. Gubbini G, Centini G, Nascetti D, et al. Surgical hysteroscopic treatment of cesarean-induced isthmocele in restoring fertility: a prospective study. J Minim Invasive Gynecol 2011; 18: 234-7.

33. Florio P, Gubbini G, Marra E, et al. A retrospective case-control study comparing hysteroscopic resection versus hormonal modulation in treating menstrual disorders due to isthmocele. Gynecol Endocrinol 2011; 27: 434-8.

34. Donnez O, Jadoul P, Squifflet J, et al. Laparoscopic repair of wide and deep uterine scar dehiscence after cesarean section. Fertil Steril 2008; 89: 974-80.

35. Yalcinkaya TM, Akar ME, Kammire LD, et al. Robotic-assisted laparoscopic repair of symptomatic cesarean scar defect: a report of two cases. J Reprod Med 2011; 56: 265-70.

Received: 29.04.2013, accepted: 12.09.2013. 